This is a self-archived version of an original article. This version may differ from the original in pagination and typographic details.

Author(s): Taipale, Joona

Title: Building bridges within and across Husserlian phenomenology

Year: 2018

Version: Published version

Copyright: (c) Taipale \& ProtoSociology, 2018.

Rights: In Copyright

Rights url: http://rightsstatements.org/page//nC/1.0/?language=en

Please cite the original version:

Taipale, J. (2018). Building bridges within and across Husserlian phenomenology. ProtoSociology : An International Journal of Interdisciplinary Research, 2018(Reviews), 1-5.

https://doi.org/10.5840/protosociology20183518 


\title{
BUILDING BRIDGES WITHIN AND ACROSS HUSSERLIAN PHENOMENOLOGY
}

\author{
Joona Taipale
}

Dan Zahavi. Husserl's Legacy. Phenomenology, Metaphysics \& Transcendental Philosophy, Oxford University Press, 20I7, 236 pp.

In the Crisis of European Sciences, Husserl proclaims that his entire life work has consisted in an attempt to clarify the "intentional correlation" between the world and the experiencing subjectivity. As Husserl goes on to explain, the phenomenological reduction - a reversal from the "ready-made world" of the natural attitude to the phenomenological constitution of the world - had been operative already in the Logical Investigations - even if it was thematised and explicated not until some years later. For Husserl, intentionality is not, literally speaking, "a relation" between subjectivity and the world. The constituted and the constituting are rather to be understood in terms of non-independent parts of a whole, which is to say that the so-called "relation" between them is reminiscent to the "relation" between the colour of an object and the spatial shape of that object. One is not graspable without the other, even if only one of the poles would gain a thematic status in the mind of the thinker. In the natural attitude, what is thematic is the world - and whenever subjectivity is considered, it is already subordinated to the former. And so, assuming that the other side the correlation is something "merely subjective", there is no sense in the Husserlian project.

The idea of an a priori "correlation" has been the target of various criticisms during the last hundred years. The various accusations issued toward Husserlian ideas have ranged from "solipsism" and "subjective idealism" to "intellectualism" and "internalism". Until the I980's or so, a rather common assumption was that Husserl's preoccupation with the correlation subordinates the world, being, and meaning to subjectivity, and (thus) leads to a dead end. The publication of the intersubjectivity volumes of the Husserliana in the mid-1970's marked a turning point in this respect. The idea that the absolute constituting subjectivity is an intersubjectivity - i.e., the idea of "transcendental intersubjectivity" - did not fit well with the old interpretation of Husserl, and since the I990's there has been a radical change in the interpretation of Husserl.

Dan Zahavi is one of the key figures, if not the key figure, in this respect. As the author of more than 25 monographs and edited volumes, and (literally) 
hundreds of articles and book chapters, Zahavi is one of the most productive philosophers of our times. His work has been, and is being, widely read and appreciated also in outside phenomenological scholarship and even outside philosophy - and for good reasons. Zahavi is a bridge builder, whose wide expertise enables bringing together various schools in philosophy and combining the theoretical and conceptual insights with empirical science yet without losing touch of the philosophical rigor.

Zahavi's latest book, Husserl's Legacy, is a major achievement. Filled with an abundance of analyses, the book discusses intentionality, reflection, introspection, the epoche and the reduction, objectivity, intersubjectivity, transcendental philosophy, the question of idealism and realism, the relationship between phenomenology and science, and the question of naturalism - just to name some of the most prominent topics. The style of the exposition is eloquent: the book is written in a relaxed way, yet without dispensing with focus or clarity. In philosophy, an eloquent style of writing is a virtue only when combined with clarity, and Zahavi does a brilliant job in this respect. The exposition proceeds in an intuitive manner: the different positions are distinguished in detail, and the text continuously supports and persuades the reader by assessing the existing and imagined objections to the presented key theses. And yet, instead of a bundle of claims, possible objections, and their refusals, the book at once presents a convincing, coherent, and comprehensive story.

To be sure, the book is about Husserl. It highlights the relevance of his philosophy, defends a particular interpretation of Husserl's ideas, and it is "intended as a contribution to Husserl scholarship". Yet, the book is not just about Husserl, but something that proves significant from the point of view of philosophy more generally. This has been a significant virtue of Zahavi's earlier publications as well. Already in his dissertation, Husserl und die Transzendentale Intersubjektivität from 1996, he paved way for ideas that nowadays are part of standard interpretation among Husserl scholars. Besides opening new horizons for exegetical explications of Husserl, and besides motivating us to rethinking the relationship between him and certain other phenomenologists, the Intersubjectivity book at once opened Husserlian thinking toward other branches of philosophy and science. It built new bridges. Also, in his habilitation, Self-Awareness and Alterity from 1999, new perspectives in Husserlian thinking were explicated and illuminated. Like our familiarity with Husserlian theory of intersubjectivity, the fact that all Husserl scholars are today familiar with the notion of pre-reflective self-awareness, is also largely owing to work done by Zahavi. Yet, also the Self-Awareness book contributed more: Husserlian 
ideas were explicated in the form that opened toward the broader scientific environment of phenomenology. One of the key strengths in Zahavi's writings is that he is able to combine the focus on and devotion to Husserl, on the one hand, and a more systematic research interest toward, well, the things themselves.

Husserl's Legacy continues in this path. In the form of an analysis of Husserlian thinking, Zahavi again delivers an in-depth analysis that may be expected to have a significant impact in the field. To be sure, in its broad scope and depth, the book is a real treasure to anyone interested in Husserl's philosophy per se. Moreover, by carefully going through the most prominent past and contemporary criticisms of Husserl, Zahavi comes to systematically underline the compatibilities and incompatibilities between phenomenology and other philosophical approaches, scientific theories, and various metaphysical standpoints.

In the light of the persistent interpretations of Husserlian philosophy, where he has been labelled as a solipsist, an internalist, a subjective idealist, a philosopher of meaning with no interest toward the real world, or an anti-naturalist adversary to science - in the light of such interpretations, Husserlian thinking has unsurprisingly been considered to be a waste of time, a philosophical dead-end, and an endeavour that is unable to learn anything from science (to say nothing of providing the latter with significant insights). By systematically going through, and dismantling, this patchwork of interpretations, and convincingly criticising these with both exegetical and systematic means, the book once again offers two things. On the one hand, it delivers a plausible comprehensive interpretation of Husserl - an interpretation that, building on decades of research on Husserl, takes into account his entire production. This, naturally, is already a great achievement by itself, and the book can be expected to be widely read by Husserl scholars, both juniors and seniors, now and in the future. On the other hand, the wider significance of the book once again relates to the fact that Zahavi firmly connects his interpretation to contemporary debates that are ongoing in the field of philosophy and science more generally. He engages with these debates. This is one of the obvious strengths of the book: far from being a piece of introverted Husserl scholarship, with the main aim of correcting certain misguided interpretations, Zahavi's new book is a piece of philosophy par excellance. To be sure, the book sets out with Husserl, it recognizes indebtedness to his work, and draws on his ideas, but it opens outward: it continuously engages in discussions with scholars and sources outside the phenomenological tradition and also outside philosophy. To put it in phenomenological terms, the book sheds light upon the internal horizon of Husserlian phenomenology, but it importantly also reveals the ex- 
ternal horizon of the latter, thus localizing phenomenology is in its academic Umwelt.

As for the mentioned Umwelt, let us draw some attention to Zahavi's analyses on the relation between phenomenology and naturalism. In Zahavi's analysis, the limits of naturalism are linked with what Husserl called the "paradox of subjectivity". In the words of Zahavi: "Naturalism treats consciousness as an object in the world (...) but this is unacceptable, since consciousness, rather than merely being an object in the world, is also a subject for the world. The decisive limitation of naturalism is that it has failed to recognize the transcendental dimension of consciousness" (pp. I45). In the words of Husserl: "the mind can be naturalized but only to a certain degree"; "subjects cannot themselves dissolve into nature for in that case what gives nature its sense would be missing" (Hua4, 297). Yet, clearly, the fact that there are limits to naturalisation does not a priori refute naturalism altogether. For sure, one could claim that phenomenology and the sciences of nature are simply discussing completely different matters when referring to "consciousness", for instance - this would entail an idea of two fundamentally distinct regions of being without mutual communication. But if one desires to avoid traversing such dualistic or parallelistic metaphysical paths, one is before soon faced with the question of the relationship between phenomenology and natural-scientific approaches to consciousness.

Zahavi elaborates on the different possible ways of conceiving a "naturalized phenomenology". First, the relationship between the two could be understood in terms of subordination. Many people associate "naturalized phenomenology" with a standpoint in which phenomenology is considered as an annex to natural science. This would abolish the transcendental (and perhaps also the philosophical) nature of phenomenology. The second option is more open to science, yet in a way that safeguards the independence of the two:

Even if phenomenology ought to pay attention to empirical findings, this does not entail that it should also simply accept the (metaphysical and epistemological) interpretation that science gives to these findings. The possibility of a fruitful exchange between phenomenology and empirical science is consequently not meant to make us deny their difference. I see no incoherence in claiming that phenomenology should be informed by the best scientific knowledge, while at the same time insisting that the ultimate concern of phenomenology is transcendental philosophical, and transcendental philosophy differs from empirical science. (pp. 163)

This proposal is "modest", as Zahavi puts it, in the sense that it does not necessitate rethinking the very relationship between the constituting and the 
constituted, between the transcendental and the natural-or between philosophy and empirical science. Yet, rather than choosing between "external scientific explanation or an internal phenomenological reflection [of consciousness, for instance]", and rather than merely pursuing forms of cooperation in which both may remain independent and separate from one another, one perhaps needs to reconsider the very opposition itself. That is to say, perhaps we should rethink what is natural and what is transcendental (pp. I67-I68).

To be sure, as pointed out, flexibility in this respect does not have to be onesided or submissive. As Zahavi points out, "naturalization of phenomenology" is just one side of the issue; the other side is the "phenomenologization of natural science". A fruitful exchange and collaboration between phenomenology and natural science is a highly important and laborious task, and a lot of reconsideration and balancing is needed. Besides considering the limits to "naturalisation of phenomenology", we should perhaps also consider the limits to the project of "phenomenologization of natural science". Be that as it may, phenomenology and naturalism can't come to understand one another, as far as they strongly hold on to their own positions and methodological assumptions. Yet, if they are related to the one and the same reality, instead of opposites, it might better to consider them in terms of a continuum. If such a metaphor is apt in the connection, the problem could be framed in terms of a question of locating the relevant points of intersection between the two. This brings up questions of compatibility as well as metaphysical issues, which are treated towards the end of the book.

With this brief summary, I can obviously only scratch the surface of Husserl's Legacy. I warmly recommend the book to anyone interested in phenomenology, but also to all scholars, juniors and seniors, whose research touches upon questions of internalism/externalism, speculative realism, naturalism, or the relation between philosophy and empirical science. All in all, Zahavi offers a very enjoyable and inspiring reading experience, without putting aside philosophical rigor and clarity.

\section{Joona Taipale}

Ph.D., Docent, Senior Lecturer (ma.)

Dept. of Social Sciences and Philosophy

University of Jyväskylä

Research project (Kone Foundation) 